\title{
Tradução como contrapoder: representações de gênero em webnotícias
}

\author{
Angélica Karim Garcia Simão* \\ Júlia Vilar Diogo**
}

Resumo: Neste trabalho, analisamos a tradução de textos jornalísticos, entendendo a tradução como um fenômeno de "representação cultural" (ZIPSER E POLCHLOPEK, 2006), e observamos os critérios utilizados por tradutores para representar a violência de gênero, considerando os procedimentos de tradução empregados. Partimos do entendimento de que o jornalismo pressupõe o fato a ser noticiado, o que diferencia o papel que tradutores e jornalistas desempenham no que tange às suas matériasprimas. Assim, pudemos refletir sobre o papel que as instituições sociais desempenham, bem como sobre seu poder e influência na transmissão de ideologias que incidem sobre a formação da opinião pública. 0 corpus de análise constitui-se de artigos publicados em português e espanhol na versão digital do jornal Folha de São Paulo, considerado o jornal de maior circulação no Brasil.

Palavras-chaves: Webnotícias; Representação; Gênero feminino; Tradução jornalística.

Abstract: This research investigates the translation of web news considering translation as a phenomenon of "cultural representation" (ZIPSER \& POLCHLOPEK, 2006), we aimed to reflect on the criteria used by the translators to represent gender violence and how these proceedings can be perceived in result of the translation process. We understand that journalism itself is associated with the reports of facts; hence, what distinguishes the role of translators from journalists are their raw materials. From this perspective, we can reflect on the role that social institutions play on the translation of journalistic texts, as well as their power and influence in the transmission of ideologies that impact on the formation of public opinion. The analyzed corpus is composed by articles published in Portuguese and Spanish in digital version of Folha de São Paulo newspaper, considered the widest circulation newspaper in Brazil.

\footnotetext{
* Docente do Departamento de Letras Modernas do Instituto de Biociências, Letras e Ciências Exatas da Universidade Estadual Paulista vinculada ao Programa de Pós-graduação em Estudos Linguísticos (Linguística Aplicada). E-mail: angelica.karim@unesp.br.

" Mestranda do Programa de Pós-graduação em Estudos Linguísticos no Instituto de Biociências, Letras e Ciências Exatas da Universidade Estadual Paulista (PPGEL-Unesp/Ibilce). E-mail: julia.diogo06@gmail.com. Pesquisa financiada pela Fundação de Amparo à Pesquisa do Estado de São Paulo (FAPESP). Proc. Nº 2018/24950-1.
} 
Key words: Web news; Representation; Feminine gender; Journalistic translation.

\section{Introdução}

Conhecer uma língua estrangeira significa muito mais do que dominar um código linguístico composto por regras e padrões gramaticais. A língua também envolve questões e padrões de ordem cultural, social e histórica que se relacionam com os indivíduos e com os contextos de suas respectivas comunidades interpretativas. Mais do que um objeto de comunicação, a língua é utilizada com intenções e objetivos variados, constituindo-se, assim, como um instrumento de manipulação e poder no qual são refletidos os valores de uma sociedade.

A compreensão do texto jornalístico, entendido como reprodutor de fatos sociais e como produto e produtor de significados nesse processo, pressupõe o reconhecimento de aspectos culturais presentes nas interações dos falantes envolvidos em diferentes contextos. Cada vez mais entende-se a influência e a relevância de tais conhecimentos culturais para a compreensão dos textos e para a realização da atividade tradutória.

No que tange à relação entre cultura e tradução, a esfera da tradução jornalística é uma das que mais expressivamente destaca essa relação e, dessa perspectiva, baseamo-nos, principalmente, em autoras como Zipser e Polchlopek (2006), que refletem sobre essa questão, entendendo "a tradução como representação cultural”, e Hernández Guerrero (2012), que explora os estudos da tradução como transmissão de ideologias, desempenhando um importante papel na formação de identidades e discursos por meio da circulação midiática.

Propomos analisar, dessa forma, a tradução enquanto representação, partindo do pressuposto de que a tradução não se dá somente a partir de línguas diferentes, mas também entre culturas e sujeitos envolvidos em diferentes processos histórico e sociais. Com isso, buscamos enfocar os mecanismos que regulam o funcionamento e os procedimentos utilizados pelos tradutores, 
entendendo que, no campo da tradução jornalística, as escolhas linguísticas, sobretudo no âmbito lexical, refletem ideologias que contribuem para a formação da opinião pública.

\section{Fundamentação teórica \\ 1.1 Léxico e cultura}

A linguagem é uma das mais importantes faculdades humanas, e a língua, dentre elas, é a que mais facilmente possibilita as trocas diárias de informação e a construção da nossa visão e apreensão da realidade. Muitos autores discorrem sobre a importância das relações que envolvem língua, cultura e representação social e que se dão no seio das sociedades, em grande parte, pela mediação midiática.

Para Caune (2014), dentre um conjunto de sistemas simbólicos nos quais a cultura pode ser caracterizada, a linguagem se situa em primeiro lugar, visto que a assimilação, a perpetuação e a transformação da cultura se dão pela língua. Para o autor, "os fenômenos linguísticos são fenômenos culturais" (CAUNE, 2014: 26). Segundo ele, a língua e a cultura são concomitantemente fundamento e produto da expressão dos indivíduos, fator pelo qual se dão suas existências: "o poder das palavras não está somente nas palavras" (2014: 23).

Também para Borba (2006), a língua, enquanto sistema, faz parte da cultura e é um espelho dos dados culturais: "o léxico [...] fisionomiza a cultura porque a representa, fixa e transmite” (BORBA, 2006: 82); dessa forma, cada comunidade vai representar o mundo a sua maneira, uma vez que "o léxico caracteriza a cultura" (2006: 84). Borba também argumenta que a esfera jornalística é uma facilitadora da interpretação cultural, visto que é pelo jornal que novas palavras são incorporadas à língua e também é por meio dele que há maior circulação dessas palavras, o que "facilita a universalização, ou seja, a generalização dos termos" (2006: 92). Para o pesquisador, a função de interação social pela língua é cumprida plenamente pelo jornal. 
A duração e expansão do mesmo evento e/ou de seus desdobramentos propiciam a formação de palavras-testemunho, que caracterizam ou tipificam o evento, podendo com o tempo, no futuro, torná-las palavras-chave para a interpretação de um modo de pensar ou de agir do grupo numa determinada época. (BORBA, 2006: 92)

Para Antunes (2012), a produção de uma memória social ocorre por meio da linguagem e, nessa esfera, o jornalismo se apresenta como um fator essencial. Aponta também que "o discurso jornalístico opera concomitantemente por meio de indicação de realidades relevantes que 'cabem' no sistema midiático, e o silenciamento de realidades semióticas outras, que exorbitam esse mesmo sistema" (2012: 148), em um processo de complexidade dos saberes construídos.

Com base nas reflexões anteriores, entendemos que processos de representação da realidade ocorrem, no âmbito jornalístico, mediados pela linguagem e que nem sempre esse processo se dá de modo objetivo.

\subsection{Gênero, léxico e jornalismo}

É através da linguagem que representamos o mundo e, por esse motivo, aspectos culturais são refletidos na língua, pois é por meio dela que conseguimos entender a cultura. Tal fato não parece diferenciar-se nas relações de gênero, que também são perpassadas pela cultura. Nessa perspectiva, a questão de gênero é entendida aqui, assim como para Hasan e Gil (2016), como categoria analítica que permite interpretar as desigualdades e como categoria política que possibilita entender as formas de distribuição do poder entre os gêneros. Como consequência, essa categoria nos permite compreender a discriminação e a subordinação das mulheres na sociedade. As autoras apontam para a importância da linguagem afirmando que:

A própria linguagem é uma ferramenta de transformação. Na linguagem se revelam valores e se evidenciam as relações de poder existentes, dando voz ou silenciando, nomeando ou ocultando. Neste sentido, a linguagem é fundamental para construir modelos de 
identificação positivos e negativos, com o quais tanto os estereótipos de gênero como a discriminação ou a violência de gênero se produzem e reproduzem constantemente, também, através das palavras que se usam e das que se omitem. (HASAN E GIL, 2016: 274)'.

Assim, não só o que se diz revela posicionamentos ideológicos, mas, sobretudo, aquilo que não é dito, isto é, o que é silenciado ou omitido pelo discurso. Sobre tais omissões no discurso, Juárez Rodríguez (2017) retoma o termo "feminicidio", cuja origem é o termo feminicide, cunhado na década de 1980 com a intenção de dar visibilidade ao componente misógino subjacente aos crimes perpetrados contra mulheres, e que foram ignorados por meio do emprego de palavras consideradas neutras, como homicídio e assassinato. (Toledo, 2009 apud Juárez RodRíGUeZ, 2017).

Tais unidades lexicais omitem o componente misógino implicado em algumas ações, ao contrário da unidade lexical "feminicidio" que, por meio da explicitação, denunciaria o uso e controle do léxico e de recursos estilísticos nas mensagens que os diferentes meios de comunicação lançam à sociedade, estando esse uso codificado pelos atores que ostentam o poder.

Ao fazer uso da unidade lexical "feminicidio", pode-se afirmar que há uma melhor conceituação nas notícias, gesto que denuncia a violência de gênero contra a mulher. Nessa esfera, entendemos que o fenômeno de nomeação ou conceituação de algumas unidades do léxico presentes na tradução jornalística (TJ) funcionam como uma forma de dar visibilidade e de não "maquiar" a realidade, atenuando o fato relatado. Assim, não só o uso como a explicitação do componente semântico existente em determinadas unidades do léxico sugere maior visibilidade das opressões às quais as mulheres estão submetidas na sociedade via linguagem.

\footnotetext{
${ }^{1}$ São das autoras esta e as demais traduções de citações em línguas estrangeiras, para textos em que não há tradução publicada em língua portuguesa.

"El lenguaje mismo es una herramienta de cambio. En el lenguaje se revelan valores y se evidencian las relaciones de poder existentes, dando voz o silenciando, nombrando u ocultando. En este sentido, el lenguaje es fundamental para construir modelos de identificación positivos y negativos, con lo cual tanto los estereotipos de género como la discriminación u la violencia de género se producen y reproducen constantemente, también, a través de las palabras que se usan y de las que se omiten." (HASAN E GIL, 2016: 274)
} 
O papel do jornalismo é de fundamental importância para a sociedade, dado que é um meio de formação de opinião pública que molda visões de mundo. Pode-se inferir, então, que as representações em linguagem são um reflexo das representações sociais, por conseguinte, as representações em linguagem das opressões que ocorrem advogam pela visibilização de uma realidade, muitas vezes, silenciada na sociedade.

\subsection{Violência e estereótipos}

De acordo com Hasan e Gil (2016), as notícias sobre feminicídio se constroem em torno de um imaginário romântico e da erotização feminina, já a violência é atenuada por traições, ciúmes, infidelidades e insubmissões ao status quo. Esse cenário revela numa contradição, pois todas as recomendações nacionais e internacionais para o tratamento midiático e jornalístico da violência de gênero estabelecem que as mortes por feminicídio não possuem nenhuma relação com a paixão, mas as enquadram em um princípio de "violação dos direitos humanos das mulheres" (2016: 268).

Os aspectos supracitados revelam que a problemática da violência de gênero teve uma hipervalorização nos meios tradicionais, porém o tratamento jornalístico recai em uma série de estereótipos que não contribuem para modificar a estrutura das relações desiguais, o que possibilita que estas situações continuem ocorrendo diariamente. Tratar as mulheres a partir de estereótipos nos meios midiáticos é uma questão abordada largamente nos estudos da representação de gênero.

A partir de uma perspectiva de gênero, a violência contra as mulheres deve ser compreendida como parte constitutiva de um sistema patriarcal que apela a ela para poder se perpetuar. A legitimidade dessa violência, como apontam Hasan e Gil (2016), é possível, em parte, pelos discursos que circulam 
na sociedade, "a violência de gênero não é somente uma forma de perpetuação do poder patriarcal, mas também é necessária para mantê-lo."2 (2016: 269).

A desigual representação social das mulheres e homens, para Rovetto (2012), é resultado do “abuso de poder”. Segundo essa autora, as pesquisas realizadas na esfera das representações de gênero na mídia ratificam a constância de um enfoque androcêntrico, restritivo e conservador, assim como apontam a insensibilidade dos meios de comunicação diante das transformações sociais agenciadas pelas mulheres nas últimas décadas. A autora ainda constata que grande parte das notícias transmitidas por jornais, tidos como confiáveis, criam uma representação imprecisa e alheia à realidade, muito mais conciliado com os interesses das instituições hegemônicas do que com os interesses dos indivíduos.

\subsection{Mídia e poder}

$\mathrm{Na}$ contemporaneidade, o jornalismo parece estar mais diretamente ligado às instituições de poder, uma vez que os jornais não possuem uma linha editorial tão definida, justamente por estarem alinhados política e ideologicamente a interesses mercadológicos, não somente àqueles de informar.

Segundo aponta Ramonet (2013), os meios de comunicação servem aos interesses dos grupos que os controlam. Contudo, há maior dificuldade em identificar esse aspecto político e ideológico nos meios de comunicação, pois acabaram por dispersar suas ideologias em função do objetivo de alcançar um maior número de leitores.

Além disso, o autor também argumenta que os meios de comunicação tiveram problemas financeiros, venderam-se e se integraram a grupos maiores, os conglomerados midiáticos (agências e portais), o que ocasiona pouca variedade de informação, pois os interesses que defendem são de seus donos,

\footnotetext{
2 "la violencia de género no sólo es una forma de perpetuación del poder patriarcal, sino que, además, es necesaria para mantenerlo.” (p.269).
} 
grandes grupos financeiros e industriais. Para o autor, os conglomerados midiáticos "são grandes atores do mercado e, ao mesmo tempo, sua missão é difundir ideologias disfarçadas de informação" (2013: 63), promovendo, assim, sua visão de mundo. Para ele, hoje em dia, os grupos midiáticos estão se comportando, aos moldes do que previu Althusser, como "ferramentas ideológicas da globalização" (2013: 63). Tal situação aponta para um processo de crise dos meios de comunicação, crise que parece ser de natureza multifatorial.

Assim, em função da forte influência que o jornalismo exerce sobre a opinião pública e da pressão que sofre das instituições de poder, faz-se necessário democratizar a informação, a fim de que ela seja um verdadeiro reflexo dos fatos e da realidade social, e não algo construído artificialmente a partir de interesses privados de instituições financeiras com o intuito de manipular o que os leitores devem ou não pensar. Dessa forma, a opinião pública não pode ser formada a partir de um único viés, sem dar margem à multiplicidade de ideias e pensamentos, pois, ao fazer isso, diminui o espectro de reflexão e informação do leitor.

\subsection{Tradução jornalística}

Do mesmo modo como o jornalismo reflete aspectos culturais, a tradução jornalística também se coloca em termos culturais, e não somente como uma transcodificação linguística. Tais valores culturais se refletem em muitas esferas: semântica, léxica e sintaticamente, independente das línguas em que ocorrem. Essa reflexão não ocorre somente no que tange aos aspectos culturais, mas também pode ser observada nos interesses das instituições de poder, uma vez que essas possuem um importante papel na formação da opinião pública.

A tradução se baseia, então, na cultura e na língua em que é produzida. "Sabendo que a língua é um dos maiores expoentes culturais, e sendo ela matéria-prima da atividade tradutória, o fator cultural torna-se indissociável da tradução" (ZIPSER \& AIO, 2011: 109). "Por isso tanto os conhecimentos da 
língua quanto da cultura estrangeira são essenciais dentre as competências tradutórias (GONÇALVES, 2006) para que o tradutor possa depreender os elementos culturais do texto-fonte e enquadrá-los na cultura-alvo" (ZIPSER \& AlO, 2011: 109). $O$ tradutor, munido de conhecimentos culturais, seja da cultura fonte ou alvo, possui mais condições para trabalhar com o texto no que tange à adequação cultural.

Há, nos textos traduzidos, "a criação de um ilusório efeito de transparência total, onde a tradução não só equivale ao texto estrangeiro, como é tomada como se ele fosse - a despeito do idioma de chegada, da linguagem que o traduz." (VENUTI, 1995: 352).

Como aponta Venuti (1995),

[...] a prática da tradução será sempre, necessariamente, condicionada pelas restrições culturais e fatores sociais que emergem do contexto de recepção. Trata-se de valores, crenças e representações ancoradas em uma hierarquia de poder e prestígio. A própria seleção de textos estrangeiros a serem traduzidos, bem como o desenvolvimento de estratégias discursivas para traduzi-los, inevitavelmente exigirá, em certo ponto e da parte do tradutor, uma tomada de posição: um alinhamento com certos grupos e instituições. (1995: 379)

Segundo Von Flotow (2013), uma "escolha pelo texto pode ser feita de um ponto de vista sociocrítico, a tradução em si mesma, pode refletir e chamar a atenção aos aspectos do texto fonte que são novos, ou inovadores, ou considerados ‘úteis' para o novo público leitor” (Von FLOTOW, 2013: 180), o que aponta para o fato de "quão flexíveis e criativos/as podem ser discursos, tradutores/as e traduções, sugerindo que pode ser possível "fazer [e reescrever] o gênero de alguém" (2013: 182).

Santos e Gorovitz (2013) tratam dos fatores ideológicos que foram apontados por Lefevere (1992), como um dos elementos que agem restringindo as escolhas do tradutor, "tanto da forma quanto do conteúdo", além de fatores econômicos e de status. Embora o autor tenha situado seu trabalho no contexto da tradução literária, acredita-se que a esfera ideológica também possa ser estendida ao âmbito da tradução jornalística, uma vez que "a esfera social também é da mesma forma [que a literária] condicionada por interesses quanto ao que noticiar e traduzir" (SANTOS E GOROVITZ, 2013: 23). 
Segundo Hernández Guerrero (2005), a tradução é responsável pela propagação de discursos globais, que interagem com discursos locais e contribuem para forjar correntes ideológicas na cultura receptora. Tais discursos ideológicos se convertem, por sua vez, na base de atitudes sociais. Dessa forma, entendemos que os textos jornalísticos contribuem para forjar correntes ideológicas, e é interessante para as pesquisas da área tentar compreender de que maneira isso ocorre e quais são os efeitos e impactos para o interlocutor que tem contato com os textos jornalísticos traduzidos.

Entretanto, como afirmam Simão e Stupiello (2017), o trabalho do tradutor é invisível, mesmo quando este torna possível a compreensão em outras línguas. Isso ocorre porque os leitores não possuem ciência dos processos de transformação pelos quais a notícia com que está tendo contato teve que passar, como "a seleção e a síntese das informações a serem traduzidas e a adaptação do contexto informativo para novos públicos" (2017: 202). As autoras tratam do papel transformador, que, segundo Bielsa e Bassnett (2009), está no poder de modificar, com a finalidade de produzir um material que possa funcionar melhor como notícia para o que é agora um novo público, isto é, trata-se de uma adaptação cultural.

Do mesmo modo, Zipser e Polchlopek (2006) dissertam que, pelo fato de as notícias acontecerem dentro ou fora do universo no qual estão inseridas, não estão isentas, portanto, de receber influências externas, especialmente culturais. Dessa forma nossa leitura dos acontecimentos é apenas uma das muitas possíveis para um mesmo fato, de acordo com a cultura para a qual se destina.

Entendido dessa forma, podemos vislumbrar processos persuasivos que acarretam, inevitavelmente, manipulações textuais. Não é exagero pensarmos que, por trás dessas ações, articulam-se interesses financeiros e mercadológicos, ou seja, há uma intenção por trás da escolha e da difusão de determinados conteúdos que não é isenta e que, portanto, envolve as condições geográficas, históricas e sociais dos sujeitos envolvidos neste processo. Ao transmitirem determinadas correntes de pensamento, objetivam controlar opiniões, baseando-se em uma política de tradução que, por sua vez, está 
vinculada e sobredeterminada por instituições sociais que são instrumentos de poder.

\section{Metodologia}

O corpus utilizado para esta pesquisa foi extraído do jornal Folha de São Paulo, versão on-line. O levantamento foi realizado nos textos de chegada, em língua espanhola, utilizando-se como palavra-chave a unidade lexical "feminicídio", no período de abril de 2018 a março de 2019. Todos os textos analisados foram traduzidos pela tradutora Azahara Martín Ortega. Nosso objetivo de análise é discutir os procedimentos de tradução, envolvendo estratégias e técnicas, mais recorrentes e suas relações com os novos efeitos de sentido observáveis no texto traduzido.

Dentre os seis textos levantados, serão foco desta análise os três textos, intitulados: "Sambista Dona Ivone Lara morre aos 97 anos no Rio de Janeiro"; "71\% dos feminicídios e das tentativas têm parceiro como suspeito"; "Encontro de autora do movimento negro e escritora que trata de feminicídio vira palanque feminista", cujas respectivas traduções para língua espanhola, publicadas também na versão em espanhol digital da Folha de São Paulo são: "Fallece Ivone Lara, icono del samba, a los 96 anos"; "La actual pareja o un ex, responsables del 71\% de los feminicidios de Brasil."; "Mesas redondas se tornan tribunas feministas en la segunda jornada de Flip.".

Estabelecemos, para procedimentos de análise, as siglas TP, para textos de partida, compostos pelos textos em língua portuguesa; e TC, para textos de chegada, compostos pelas respectivas versões para a língua espanhola. Tratase, portanto, de um corpus bilíngue na direção português-espanhol. Cabe ressaltar que os textos traduzidos para a língua espanhola trazem um link na plataforma do jornal por meio do qual pode-se acessar o artigo no de partida. 
As estratégias, segundo Hurtado Albir (2001), são procedimentos conscientes, ou não, e individuais utilizados na resolução de um problema de tradução que se caracterizam por conter um elemento de planejamento, buscar certos objetivos e estarem relacionadas a uma série de ações desenvolvidas durante o processo tradutório. Podem ser verbais ou não verbais, internos (cognitivos) e externos, utilizados pelo tradutor para melhorar sua eficácia em função de suas necessidades específicas. Já as técnicas de tradução são os procedimentos concretos que se manifestam na materialidade textual e podem ser observados no texto traduzido.

Embora a autora julgue pertinente diferenciar técnicas de estratégias, optamos por utilizar, neste trabalho, o termo mais abrangente "procedimentos", pois analisamos tanto as ocorrências concretas verificadas na tradução (técnicas) quanto as decisões (estratégias) que, por inferência, acreditamos terem motivado as escolhas do tradutor.

\section{Análise de dados}

\subsection{Elisões}

Hernández Guerrero (2006) aponta que, no caso dos gêneros jornalísticos informativos, os originais são utilizados como base para criar um novo texto que deve funcionar como notícia para um público diferente e se inserir em novas convenções textuais. Por isso, não raro, independentemente do espaço designado, ocorre com frequência a elisão de partes do texto (com informação que não se considera relevante para o novo leitor), procedimentos necessários para que a notícia funcione como tal em um novo marco comunicativo. Apresentamos a seguir dois segmentos do TP2 que, de nosso ponto de vista, são de grande relevância e que foram excluídos da tradução do TC2.

TP2: "De cada 4 suspeitos, 1 tinha histórico de violência ou antecedentes criminais." 
TP2: "Scarance destaca que a separação é um dos principais fatores de risco para o feminicídio, quando associada à perseguição incessante, menções a suicídio pelo agressor e histórico de violência."

Nos trechos acima podemos perceber dois aspectos do feminicídio que constroem o cenário no qual esse crime ocorre, ou seja, aspectos instituidores do crime: o histórico de violência do agressor e a separação entre a vítima e agressor, sendo esse último, considerado por Scarance, autor mencionado na notícia, um dos principais fatores de risco para que o crime ocorra.

Nas traduções dos textos 1 e 3 , observamos que os lides foram omitidos. A elisão de lide é uma característica com alta frequência na tradução de textos jornalísticos, em função das convenções tipográficas que variam em diferentes culturas. Como podemos observar em:

TP1: "Sambista Dona Ivone Lara morre aos 97 anos no Rio de Janeiro.

Assistente social, cantora e compositora transitou por diferentes universos ao longo da vida"

TC1: "Fallece Ivone Lara, icono del samba, a los 96 años"

TP3: "Encontro de autora do movimento negro e escritora que trata de feminicídio vira palanque feminista. Bell Apuã declamou texto inspirado em trecho do poema 'Cantares do Sem-nome e de Partidas"

TC3: "Mesas redondas se tornan tribunas feministas en la segunda jornada de Flip."

Outra elisão ocorre também no corpo do texto 3, em referência à editora "Companhia das Letras":

TP3: “Autora de 'Quem Tem Medo do Feminismo Negro' (Companhia das Letras), Djamila explicou da sua dificuldade em compreender e nomear a sensação de inadequação que a perseguiu boa parte da vida."

TC3: "La autora de "Quién tiene miedo del feminismo negro", Djamila explicó su dificultad para comprender y verbalizar la sensación de inadaptación que la persiguió durante buena parte de su vida."

Acreditamos que a elisão de "Companhia das Letras" pode ter sido motivada pelo fato de que, para o leitor em língua espanhola, essa informação 
não teria tanta relevância, dado que não possui conhecimento acerca das editoras brasileiras.

Há seis parágrafos no texto em português que foram excluídos na tradução do texto para o espanhol; em contrapartida, há dois parágrafos com informações novas que não estão contidas no texto em português. Com exceção de um parágrafo que trata da filósofa Djamila Ribeiro, os cinco seguintes tratam da escritora argentina Selva Almada e da poetisa pernambucana Bell Puã. Acreditamos que por essa razão tal elisão possa ter motivação no fato de que o foco da notícia é a filósofa Djamila Ribeiro.

Há também elisões de parágrafos no texto "Sambista Dona Ivone Lara morre aos 97 anos no Rio de Janeiro", conforme explicitamos nos trechos a seguir:

TP1: Depois da aposentadoria, aos 56 anos, a carreira de cantora e compositora decolou. Dona Ivone se apresentou na Europa, na África, nas Américas. Em 2002, recebeu o Prêmio Caras de Música na categoria Melhor Disco de Samba, com o CD Nasci para Sonhar e Cantar. Em 2010, foi a grande homenageada no Prêmio da Música Brasileira. Dois anos mais tarde, ela se tornaria o tema do sambaenredo da escola do coração, a Império Serrano.

Este parágrafo foi completamente elidido na tradução para o espanhol e, de nossa perspectiva, ocorre a elisão de informações significativas, pois tratam de momentos importantes da carreira de Dona Ivone Lara. Há a elisão, ainda, do terceiro, quarto, quinto e oitavo parágrafos do TP1.

\subsection{Amplificações}

De acordo com Hernández Guerrero (2006), a amplificação linguística consiste em introduzir informações que não estão presentes no texto de partida. No caso da tradução jornalística, é de uso frequente e necessária, em decorrência das novas circunstâncias de recepção do texto traduzido. A amplificação se utiliza com diferentes finalidades. Vejamos exemplos: 
TC1: "El segundo factor que hizo que tardase en dedicarse exclusivamente a la música era el machismo - se si [sic] por los celos del marido o por el simple hecho de que no había espacio para una mujer mostrar sus canciones en los clubes de samba. (grifo nosso)"

Todo segmento que aparece no TC1 citado anteriormente é inexistente no TP1, isto é, foram acrescentadas ao texto informações que não apareciam no texto em português, trata-se de informações novas. Destacamos, ainda, além da introdução de todo o segmento citado, também a presença das unidades lexicais (em negrito) "machismo", "celos del marido" e "no haber espacio para una mujer", que aportam importantes matizes de sentido à tradução.

A primeira informação nova trata da culpa do marido de Ivone Lara, qualificado como ciumento e responsável por atrasar sua carreira. Podemos observar no segmento abaixo o contraste entre essas informações, pois ressaltase, no texto de partida, o papel de importância do marido para o desenvolvimento da carreira da cantora Ivone Lara. 0 machismo é apresentado na tradução como outro fator responsável por este atraso. No exemplo que segue, podemos observar a diferença no tratamento do marido de Ivone Lara no que tange à influência que teve sobre sua carreira:

TP1: "Além de Mestre Fuleiro, outros laços familiares foram importantes para o desenvolvimento musical de Dona Ivone Lara. Aos 26 anos, casou-se com Oscar Costa, filho de Alfredo Costa, fundador da escola de samba Prazer da Serrinha. Foi Oscar quem levou o amigo Silas de Oliveira para a agremiação."

Outro acréscimo ocorre a partir da retomada da falta de espaço para mulheres nos clubes de samba, em função do machismo, e aborda esse espaço como um ambiente masculinizado, mais uma vez sem a explicitação do trecho em português por se tratar de uma informação integralmente nova.

TC1: "Su nombre empezó a surgir em um ambiente masculinizado (grifo nosso)."

Em seguida, a entrada de Ivone Lara na escola de samba é tratada como uma revolução, outro fator que não havia sido mencionado no texto em português, ou seja, outro acréscimo. Observemos: 
TP1: “Em 1965, Dona Ivone entraria definitivamente para a história do samba. Com Silas de Oliveira e Bacalhau, compôs “Os Cinco Bailes da História do Rio" - era o primeiro samba-enredo oficial assinado por uma mulher."

TC1: “En 1965, con 'Los Cinco Bailes de la Historia de Río', en colaboración con Silas de Oliveira y Antonio Bacalao, una revolución (grifo nosso): se convirtió en la primera mujer en entrar en el ala de compositores y ganar el concurso que escogía el samba [...]"

Nos segmentos anteriores, bem como nos que seguem abaixo, surgem informações que não estão presentes no texto em português, acréscimos que acreditamos ser uma perspectiva atravessada por ideologias sociais, como o feminismo, que mais uma vez enfatizam, na tradução para o espanhol, o aspecto revolucionário de Ivone Lara.

TC1: "En un país aún hoy con un alto índice de feminicidio de mujeres negras, Ivone revolucionó (grifo nosso) sin alarde, con elegancia, por el arte."

Tais mudanças podem ter sido motivadas pelo fato de que, ao fazê-las, a tradutora Azahara Martín Ortega partiu de seu papel social como jornalistatradutora. Como foi apontado por Zipser e Aio (2011), o vínculo maior do jornalista é com o fato e, por isso, traz informações novas que não estavam contidas no texto em português. Por essa razão, a tradutora pode ter buscado informações em outras fontes que não o texto de partida, motivo pelo qual se deram as amplificações no texto. Tais alterações configuram um texto novo, diferente do de partida, revelando preocupar-se com o seu ofício de jornalista em “narrar e compartilhar o presente” (RESENDE, 2012: 158).

Um fator a ser ressaltado na tradução da manchete apresentada a seguir é o acréscimo, ao adicionar ao título a referência ao marido ou namorado anterior por meio das unidades lexicais “o un ex", apresentadas como tradução para a lexia simples presente no texto de partida "parceiro".

TP2: "71\% dos feminicídios e das tentativas têm parceiro como suspeito."

TC2: “La actual pareja o un ex, responsables del $71 \%$ de los feminicidios de Brasil." 
Tal tradução parece ser perpassada por um viés ideológico, porém vale ressaltar, como apontou Von Flotow (2013), que "nenhuma tradução é produção somente do/a tradutor/a" (2013: 171), já que o produto tradutório pode ser resultado de uma colaboração entre editores(as), revisores(as) e tradutores(as). Dessa forma, não podemos afirmar que todas essas escolhas foram unicamente feitas pela tradutora.

Isso posto, nota-se que tal tradução e tais acréscimos podem ser percebidos a partir de uma perspectiva feminista cuja intenção foi a de ressaltar o espaço que a mulher, Ivone Lara, possuía na música. Para além de uma perspectiva feminista, há também um engajamento político em tal tradução, fenômeno este apontado por Resende (2012) a partir de Flusser: "a sociedade informática emergente, nos impõe um engajamento político cujo propósito deve ser o de injetar 'valores' nas formas emergentes" (FLUSSER, 2008 apud RESENDE, 2012: 154); tais formas "emergentes" podem ser interpretadas, nesse contexto, como as traduções.

Dessa forma, a tradutora se coloca em um espaço de questionamento ao ir além das barreiras de informação oferecidas pelo texto de partida, em português, e buscar fatos em outras fontes, como aponta Resende (2012): “no entender desta proposta de reflexão, está em questão a necessidade de reconhecermos a demanda pela compreensão e aceitação de um 'nível de consciência novo' [...], que nos coloca interrogantes sobre valores dados como estabelecidos" (2012: 153). Os valores dados como estabelecidos, podem ser interpretados, neste contexto, como as informações apresentadas na notícia em português, o texto-fonte. Nota-se, então que, no que tange ao texto-fonte, "não há [...] uma problematização dos modos possíveis de narrar os fatos, mas um esforço de reiteração de valores - no caso, a verdade - que teoricamente preservam os limites do campo" (RESENDE, 2012: 157).

\subsection{Deslocamentos semânticos do léxico}


Um dos procedimentos que encontramos e que não é relatado por Hernández Guerrero (2006), nem por Hurtado Albir (2001), é o que denominamos "deslocamentos semânticos do léxico", categoria que definimos como a mudança semântica que ocorre ao optar-se, na tradução, por usar outra palavra que não aquela mais próxima, em termos de matizes semânticos, de uma tradução literal, e que acionaria no leitor matizes mais próximos, ou pertencentes a um mesmo campo, produzindo, assim, efeitos de sentido semelhantes. Tal fato acaba por alterar o sentido do texto de chegada, ou distanciá-lo semanticamente do texto de partida.

TP2: "71\% dos feminicídios e das tentativas têm parceiro como suspeito."

TC2: "La actual pareja o un ex, responsables del $71 \%$ de los feminicidios de Brasil."

Neste exemplo, pode-se notar a diferença da carga semântica na utilização das palavras "suspeito" e "responsável". No texto em português, o agente da ação é suspeito e não responsável, a utilização da unidade lexical "responsável", culpabiliza mais o autor do crime do que a unidade lexical "suspeito", em função de, no segundo, haver a confirmação da responsabilidade sobre a ação.

No dicionário de língua portuguesa Houaiss (2009:1796) a definição de "suspeito" é: "de cuja existência, exatidão ou legitimidade não se tem certeza; que inspira desconfiança ou suspeitas; diz-se de ou indivíduo sobre quem recaem suspeitas de ser o autor, o culpado de algo". Também no dicionário Houaiss (2009:1653), a definição do lexema "responsável" aparece como "aquele que responde pelos seus atos ou pelos de outrem; que têm condições morais e/ou materiais de assumir compromisso; que ou aquele que tem culpa, que foi causador (de algo); que ou aquele que possui responsabilidade".

Nos trechos a seguir, podemos observar outros deslocamentos semânticos devido à escolha de diferentes unidades lexicais para a tradução no espanhol:

TP2: "71\% dessas mulheres - as que morreram e as que sobreviveram." 
TC2: "7 de cada 10 víctimas de feminicidio, o tentativa."

Percebe-se um contraste em tratar as mulheres como "as que morreram e as que sobreviveram" e as que "foram vítimas de feminicídio, ou tentativa". A dissimilitude consiste em tratar a mulher como vítima do feminicídio e tratála como alguém que morreu. Há heterogeneidade em tratar mulheres como sobreviventes e como vítimas de uma tentativa de feminicídio, uma vez que, ao tratá-las como vítima de feminicídio, há uma explicitação de que foi um crime de gênero, e que a mulher foi uma vítima deste, denunciando e visibilizando o componente misógino que subjaz a estes crimes. Como já apontado, essa explicitação denunciaria o uso e controle do léxico e de recursos estilísticos nas mensagens que os diferentes meios de comunicação lançam à sociedade. Continuamente, há uma diferença de escolha lexical que altera a semântica da frase, que ocorre devido ao uso da passiva: a palavra "víctima" confere mais visibilidade à mulher do que aquela que foi "vitimada", como podemos constatar em:

TP2: A análise, que abrange crimes ocorridos em 25 estados, mostra que a mulher vitimada pelo crime tem, em média, 33 anos, e o agressor, um pouco mais: 38 anos.

TC2: El análisis, que recoge los crímenes de 25 estados, muestra que la mujer víctima tiene, de media, 33 años, y el agresor, 38.

Outro aspecto a ser ressaltado é a conceituação do que é feminicídio, recorrente nos textos jornalísticos e importante para visibilização de tal crime. Entretanto, a conceitualização que se faz do termo é diferente no texto em português e na tradução para o espanhol.

TP2: "um tipo de homicídio cometido 'contra uma mulher por sua condição de sexo feminino' (a palavra 'gênero', na redação inicial do projeto, foi trocada por 'sexo feminino' para aprovação do Congresso)." (grifo nosso)

TC2: "es un atentado contra la vida de la mujer por su condición de género." (grifo nosso)

Destacamos, aqui, a diferença na utilização de "condição de sexo feminino" e "condición de gênero", e principalmente pelo fato de que o termo gênero no texto, utilizado no Código Penal de 2015 em português, foi 
substituído por "sexo feminino", para aprovação do Congresso. Essa mudança nas unidades lexicais mostra o quanto escolhas linguísticas e lexicais interferem e moldam a língua e a cultura de um país. Também é interessante notar os usos das unidades lexicais "atentado" e "homicídio". No dicionário de língua portuguesa Houaiss (2009: 213), a definição de "atentado" é: “infração das disposições legais; ato criminoso ou tentativa de sua perpetração contra pessoas, ideias etc.; ato ofensivo; violação". Também no dicionário Houaiss (2009: 1031), a definição do lexema "homicídio" é: "destruição, voluntária ou involuntária, da vida de um ser humano; assassínio, assassinato".

\subsection{Modulação}

Nesta categoria, a mudança na disposição dos dados no texto traduzido, quando comparado ao texto de partida, ocasiona uma modulação, denominada por Hurtado Albir (2001) como uma mudança de ponto de vista, de enfoque ou de categoria de pensamento em relação à formulação do texto de partida, que pode ser tanto lexical como estrutural. É importante analisar as manchetes dos textos, uma vez que a manchete tem a função primordial de atrair o leitor para os conteúdos dos textos de um jornal (SALORENZO, 2018: 23).

TP1: "Sambista Dona Ivone Lara morre aos 97 anos no Rio de Janeiro"

TC1: "Fallece Ivone Lara, icono del samba, a los 96 años"

No caso da tradução da manchete dessa notícia, a ênfase foi dada à morte da sambista. Na manchete em português, o foco é a sambista e, posteriormente, é dada a informação sobre sua morte.

Há outra mudança de foco, ou seja, outra modulação no texto:

TP1: "era o primeiro samba-enredo oficial assinado por uma mulher"

TC1: "la primera mujer en entrar en el ala de compositores"

A forma como os dois textos trazem o mesmo fato é distinta: a tradução da notícia focalizou a ação realizada pela cantora como uma revolução. No 
texto de partida em português, podemos observar que o foco é tirado de Ivone, devido ao uso da passiva, e dado ao samba-enredo. Na tradução para o espanhol a cantora se tornou sujeito da frase, isto é, deixou de ser objeto. Dessa forma, no texto em português, a força e seu poder agentivo são depositados em "o primeiro samba-enredo", já na tradução, a força e o poder são deslocados para a figura da sambista.

\subsection{Tradução literal e criação discursiva}

Segundo Hurtado Albir (2001), a tradução literal ocorre quando se traduz palavra por palavra um sintagma ou expressão. Já a criação discursiva realizase quando se estabelece uma equivalência efêmera, totalmente imprevisível fora de contexto.

TP3: "Encontro de autora do movimento negro e escritora que trata de feminicídio vira palanque feminista."

TC3: "Mesas redondas se tornam tribunas feministas en la segunda jornada de Flip."

Nota-se que há uma tradução não literal, isto é, poucos elementos são traduzidos literalmente, um título totalmente novo, ou seja, uma criação discursiva, com poucos traços do que era contido no texto em português, como ao traduzir "palanque feminista" por "tribunas feministas", criado a partir de informações do texto.

TP3: "versou principalmente sobre a pluralidade e nuances do movimento feminista, sobre feminicídio e racismo, em especial contra mulheres negras."

TC3: "versó principalmente sobre la pluralidad y los matices de la corriente feminista, sobre el feminicidio y el racismo, en especial contra mujeres negras."

É interessante observar neste outro exemplo em que o texto é traduzido palavra por palavra, porém, propõe como tradução para a unidade lexical “movimento", do português, a unidade “corriente”, em espanhol. As palavras 
"movimento" e "corrente" possuem significados distintos nos estudos sobre feminismo. De acordo com Saffioti (1987), o movimento feminista é composto por várias correntes, dessa forma entendemos que a unidade lexical "corrente" não pode ser substituída pela unidade "movimento", tanto em língua espanhola como em língua portuguesa. Observamos, na contemporaneidade, o uso frequente do termo "feminismos", que resgata essa ideia de movimento composto por várias correntes. Nas palavras da autora:

$\mathrm{Na}$ segunda metade da década de 60 , começaram a surgir os movimentos feministas que, cada um seu modo, passaram a lutar pela igualdade nas relações de gênero. É preciso tomar cuidado com o termo feminismo. Rigorosamente, não existe um só feminismo, pois há diferenças de bandeiras levantadas, de ênfase posta numa ou noutra reivindicação, de estratégias de luta. Tais distinções decorrem do enfoque político dado por cada grupo ou movimento feminista a questão feminina. E há diferenças apreciáveis entre os vários feminismos. (1987: 93)

No terceiro parágrafo do texto em espanhol, há uma literalidade na tradução:

TP3: “Autora de 'Quem Tem Medo do Feminismo Negro' (Companhia das Letras), Djamila explicou da sua dificuldade em compreender e nomear a sensação de inadequação que a perseguiu boa parte da vida."

TC3: "La autora de "Quién tiene miedo del feminismo negro", Djamila explicó su dificultad para comprender y verbalizar la sensación de inadaptación que la persiguió durante buena parte de su vida."

Dado tais fatos apresentados, lembremos que o papel social da imprensa é justamente o de moldar opiniões, uma vez que é o noticiário que abastece as mentes com informações, passando a constituir representações e estereótipos no imaginário coletivo.

\subsection{Compensação}


De acordo com Hurtado Albir (2001), a compensação ocorre quando se introduz no lugar do texto traduzido um elemento de informação ou efeito estilístico que não se encontra no mesmo lugar em que aparece situado no texto de partida.

TP1: "Sambista Dona Ivone Lara morre aos 97 anos no Rio de Janeiro.

Assistente social, cantora e compositora transitou por diferentes universos ao longo da vida"

TC1: "Fallece Ivone Lara, icono del samba, a los 96 años"

A primeira compensação que vale aqui destacar ocorre na manchete do texto. Quanto à idade de Ivone Lara, a tradutora utiliza-se de informações contidas no corpo do texto em espanhol, segundo o qual Dona Ivone Lara teria completado 96 anos. Assim, opta por, em vez de tratar sobre este dado no corpo do texto, elucidá-lo já na manchete. Obtém-se, assim, um resultado diferente entre as manchetes no tratar da idade de Ivone Lara, no texto em português, 97 anos, e no texto em espanhol, 96 anos, havendo discrepância entre as idades.

Outra compensação que ocorre ainda neste texto é sobre o fato de Dona Ivone Lara ter sido enfermeira e ter trabalhado com Dra. Nise da Silveira. Tais informações aparecem no início do texto de chegada, enquanto, no texto de partida, aparecem no final.

Há também uma síntese na forma de apresentar essas informações. Vejamos:

TP1: "Quando jovem, movida pelo desejo de ter um emprego estável, matriculou-se na Escola de Enfermagem Alfredo Pinto, no Rio de Janeiro. 'Muita gente fazia enfermagem. Eu mesma trabalhei com uma porção de pessoas do meio do samba dentro dos hospitais... Trabalhei, por exemplo, com a mãe do Paulinho da Viola, mulher de seu Paulo Faria, que já era músico respeitado. Mas ela mantinha o seu emprego estável.' A profissão de enfermeira e, mais tarde, assistente social, também rendeu testemunhos de fatos importantes da história brasileira. Dona Ivone trabalhou com Dra. Nise da Silveira, uma das pioneiras do tratamento mais humano em clínicas psiquiátricas."

TC1: “Ivone se graduó en enfermería y se especializó en asistencia social. 
Se convirtió en el brazo derecho de Nise da Silveira, cuidando durante 37 años de pacientes con trastornos mentales. No es por acaso que la sensibilidad y humanismo se revelan en su faceta artística."

TC1: "De manera inteligente y discreta, comenzó a presentar sus composiciones como si fueran de sus primos, Maestro Fuleiro y Tío Helio."

Neste excerto, podemos notar um viés do machismo presente na sociedade pelo fato de uma mulher, neste caso Ivone Lara, ter que apresentar sua canção como se estivesse sido escrita por homens.

Há no trecho a seguir uma apreciação no texto de chegada, que parece demonstrar o caráter subjetivo da tradução, visibilizado pela inserção da unidade lexical "una revolución":

TP1: "Foi Oscar quem levou o amigo Silas de Oliveira para a agremiação. Em 1965, Dona Ivone entraria definitivamente para a história do samba. Com Silas de Oliveira e Bacalhau, compôs 'Os Cinco Bailes da História do Rio' -era o primeiro samba-enredo oficial assinado por uma mulher."

TC1: "Su nombre empezó a surgir en un ambiente masculinizado. En 1965, con 'Los Cinco Bailes de la Historia de Río', en colaboración con Silas de Oliveira y Antonio Bacalao, una revolución: se convirtió en la primera mujer en entrar en el ala de compositores y ganar el concurso que escogía el samba-enredo que la escuela iba a llevar al desfile."

Tal inserção torna visível a manifestação de uma voz que assinala para um gesto revolucionário, como a inserção da unidade lexical "revolucionó" no fragmento abaixo:

TC1: "En un país aún hoy con un alto índice de feminicidio de mujeres negras, Ivone revolucionó sin alarde, con elegancia, por el arte.

Ivone nunca fue líder de ventas, pero sus composiciones se dispersaron (y aún se reverberan) por todo el país." (grifo nosso)

Como discutido ao longo deste trabalho, a utilização da unidade lexical "feminicidio" é importante, principalmente dentro do campo da enunciação jornalística, pois é uma forma de denunciar e visibilizar o componente misógino que subjaz estes crimes, gesto que denuncia a violência de gênero contra a mulher, uma forma de visibilidade e de não "maquiar" a realidade. 
No trecho apresentado temos, então, como um aspecto importante dessa visibilidade, além da introdução da unidade lexical "revolucionó”, que não estava presente no texto em português, a introdução também da expressão "en un país aún hoy con un alto índice de feminicidio de mujeres negras", para ressaltar como, em função do cenário brasileiro da época, Ivone Lara foi “revolucionária” em suas ações e comportamentos.

\section{Considerações finais}

No presente trabalho, por meio de uma reflexão em torno dos critérios utilizados para representar o gênero feminino, foram analisados os procedimentos tradutórios empregados na tradução do português para o espanhol. Estabelecemos como categorias de análise, seguindo as considerações de Hurtado Albir (2001), as técnicas de elisão, amplificação, modulação, tradução literal, criação discursivas e incluímos os "deslocamentos semânticos do léxico". Também foi discutido o papel das instituições sociais na tradução dos textos jornalísticos, aqui abordados a partir da influência que as instituições financeiras têm sobre a mídia, partindo do entendimento de que os meios de comunicação tiveram problemas financeiros, venderam-se e se integraram a grupos maiores, os conglomerados midiáticos (agências e portais).

Buscamos discutir o quanto essas instituições delimitam as linhas editoriais jornalísticas, fazendo com que a mídia fique diretamente ligada e alinhada política e ideologicamente a interesses privados e hegemônicos, além de apresentar um papel fundamental na difusão de ideologias sob o rótulo de informação, ou seja, desempenham um grande poder e influência na transmissão de ideologias.

Partimos da hipótese, orientada pela literatura na área de gênero, que apresentava o diagnóstico da persistência de um olhar informativo androcêntrico, assim como a falta de sensibilidade dos meios de comunicação 
para dar conta das transformações sociais experenciadas pelas mulheres nas últimas décadas.

Tal fato foi constatado nos textos originais em português, porém, no âmbito da tradução do corpus analisado, constatamos aspectos muito diferentes, pois não há um olhar androcêntrico presente na tradução dos textos, mas sim uma perspectiva feminista. Acreditamos que o fato da jornalistatradutora ser mulher possa ter influenciado as escolhas tradutórias, assim como suas ideologias, para além do fato de que as mulheres não foram representadas a partir de estereótipos de gênero.

A partir das mudanças observadas na tradução, coloca-se em questão os limites entre tradução e adaptação, assim como princípios de fidelidade apoiados nas noções de objetividade e neutralidade. Os textos em questão analisados, devem ser entendidos como traduções, e não adaptações, pois as mudanças observadas, independentemente de sua natureza ideológica, são esperadas dentro do processo tradutório, sobretudo em traduções de textos jornalísticos.

Dado que, no processo da enunciação, exige-se um engajamento conforme apontado por Resende (2012) neste trabalho, podemos afirmar que a tradutora vai, pois, na direção contrária ao discurso hegemônico, ou seja, este que entende a objetividade como fidelidade.

A partir da inserção de novas unidades lexicais como "machismo", reconhece-se as marcas de subjetividade, não apresentadas no texto-fonte. À vista disso, ao problematizar questões sociais do gênero feminino, optou-se por visibilizar-se estas marcas de subjetividade que não foram antes apresentadas. Logo, “a objetividade deve ser reconsiderada à luz dos espaços e dos modos narrativos, trabalhando, também, num plano de ressignificação das formas narrativas" (RESENDE, 2012: 161). Neste quadro, é a tradução então que ressignifica, ou seja, enquanto o jornalismo ressignifica o fato, a tradução ressignifica a informação, o que pôde ser observado nos dados analisados, nos quais a tradutora ressignificou os textos, ao inserir novas informações e unidades lexicais. 
No que tange ao poder e à influência que os meios de comunicação de massa desempenham na transmissão de ideologias, Ramonet (2013) discorre: "a imprensa faz, constrói, cria opinião pública” (RAmOnet, 2013: 65). Nessa perspectiva, o autor destaca que a opinião pública se qualifica como o quarto poder, mas que não está funcionando corretamente, uma vez que deveria ser um contrapoder. Assim, levanta o questionamento de que o poder midiático é o único sem contrapoder e, por esse motivo, não é democrático, em função dos interesses mercadológicos que passaram a orientá-lo.

Diante dos dados apresentados, observamos que, apesar de haver na contemporaneidade uma pasteurização dos meios de comunicação, ou seja, uma perda da orientação político-ideológica, dado que a mídias estão associadas a instituições econômicas e financeiras, preocupando-se em veicular mais os interesses destas a fim de conquistar um maior público leitor, percebemos que, por outro lado, nas traduções analisadas, existiram indícios de que essa pasteurização não aconteceu.

No contraste entre os textos de partida e textos de chegada, pudemos perceber deslocamentos de sentidos causados pela instauração de unidades lexicais carregadas ideologicamente de matizes feministas, como: "machismo", "celos del marido" e "no había espacio para una mujer". Tais aspectos nos levam a refletir sobre os limites da tradução e as próprias questões que caracterizam os gêneros jornalísticos. Tais diferenças vão além das dimensões espaciais do texto que se restringem ao número de caracteres entre os textos de partida e textos de chegada, uma vez que o que se destaca é a diferença entre a densidade ideológica do texto traduzido, entendendo aqui "densidade ideológica" como um aprofundamento de questões ideológicas como o feminismo, a partir da introdução de unidades lexicais marcadamente feministas que não estavam presentes no texto de partida em português.

Foram utilizadas unidades do léxico que se situam no interior de um discurso que se pretende feminista, que explicitam um caráter machista que não estava presente no texto de partida. Isso posto, e analisando como a tradução modificou o texto em português, em função das grandes diferenças observadas entre eles, podemos concluir, até o momento, que a tradução, na 
falta de um contrapoder para a mídia, instaurou-se como um espaço de contrapoder que não encontra reverberação na redação dos textos jornalísticos analisados.

\section{Referências}

ALBIR, A. H. Traducción y Traductología. Introducción a la traductología. Madrid: Ediciones Cátedra, 2001, p. 695

ANTUNES, E. Novos valores impressos. In: FRANÇA, V. R. V.; CORRÊA, Laura Guimarães. (Org.). Mídia, instituições e valores. 1ed. Belo Horizonte: Autêntica, 2012, pp. 147-151.

Borba, F. S. Léxico e Herança Social. In: Marchezan, R.C., Cortina, A. (Org.). Os fatos da linguagem, esse conjunto heteróclito. Série Trilhas Linguísticas n. 10. 1ed. Araraquara: Cultura Acadêmica Editora, 2006, pp. 81-96.

BURNs, M. Sambista Dona Ivone Lara morre aos 97 anos no Rio de Janeiro. Folha de São Paulo. São Paulo, 17.abr.2018. Disponível em: <https://www1.folha.uol.com.br/ilustrada/2018/04/sambista-donaivone-lara- morre-aos-97-anos-no-rio-de-janeiro.shtml>. Acesso em: 5 junho 2019.

BURNs, M. Fallece Ivone Lara, icono del samba, a los 96 años. Tradução: MARTín, A. Folha de São Paulo. 18. abr. 2018. Disponível em: <https://www1.folha.uol.com.br/internacional/es/cultura/2018/04/1 965362-fallece-dona-ivone-lara-icono-del-samba-a-los-96-anos.shtml> . Acesso em: 5 junho 2019.

Carazzal, E. H.; Canofre, F.; Barbon, J.; Zaremba, J. e Sperb, P. $71 \%$ dos feminicídios e das tentativas têm parceiro como suspeito. Folha de São Paulo. Curitiba, Belo Horizonte, Rio de Janeiro, São Paulo e Porto Alegre, 8.mar.2019. Disponível em: <https://www1.folha.uol.com.br/cotidiano/2019/03/71-dosfeminicidios-e-das-tentativas-tem-parceiro-como-suspeito.shtml>. Acesso em: 5 junho 2019. 
Carazzal, E. H.; Canofre, F.; Barbon, J.; Zaremba, J. e Sperb, P. La actual pareja o un ex, responsables del $71 \%$ de los feminicidios de Brasil. Tradução: MARTín, A. Folha de São Paulo. 8.mar.2019. Disponível em: <https://www1.folha.uol.com.br/internacional/es/brasil/2019/03/laactual- pareja-o-un-ex-responsables-del-71-de-los-feminicidios-debrasil.shtml >. Acesso em: 5 junho 2019.

CAUne, J. Cultura e Comunicação: Convergências teóricas e lugares de mediação. Trad. Laan Mendes de Barros. São Paulo: Editora Unesp, 2014.

HASAN, V. F; GIL, A. S. La Comunicación con enfoque de género, herramienta teórica y acción política. Medios, agenda feminista y prácticas comunicacionales. El caso de Argentina. Revista Estudios de Género La ventana, v. 5, n. 43, Argentina, enero-Julio, 2016, pp. 246-280. Disponível em: http: / / www.scielo.org.mx/scielo.php?script=sci_arttext\&pid=S140594362016000100246\&lng=es\&nrm=iso. Acesso em: 5 junho 2019

HeRnández GuerRero, M. J. La traducción de los géneros periodísticos. In: CoRTÉs ZABORRAS, C. e HERNÁNDEZ GUERRERO, M. J. (Org.). La traducción periodística. Cuenca: Ediciones de la Universidad de Castilla-La Mancha, 2005, pp. 89-135.

HeRnÁndez Guerrero, M. J. La traducción al servicio de una línea editorial: la primavera árabe en el diario El País. Meta, v. 57, n. 4. España, 2012, pp. 960-976.

HeRnández Guerrero, M. J. Técnicas específicas de la traducción periodística. Quaderns. Revista de traducción 13, n. 13, Málaga, 2006, pp. 125-139.

HoualsS, A.; VILLAR, M. S. Dicionário Houaiss de Língua Portuguesa. Elaborado pelo Instituto Antônio Houaiss de Lexicografia e Banco de Dados da Língua Portuguesa S/C Ltda. Rio de Janeiro: Objetiva, 2009.

Mena, F.; Mello, P. C. Mesas redondas se tornan tribunas feministas en la segunda jornada de Flip. Tradução: MARTíN, A. Folha de São Paulo. 27.jul.2018. Disponível em: <https://www1.folha.uol.com.br/internacional/es/cultura/2018/07/1 977050-mesas-redondas-se-tornan-tribunas-feministas-en-la-segundajornada-de-flip.shtml>. Acesso em: 5 junho 2019.

Mena, F.; Mello, P. C. Encontro de autora do movimento negro e escritora que trata de feminicídio vira palanque feminista. Folha de São Paulo. Paraty, 26.jul.2018. Disponível em: <https://www1.folha.uol.com.br/ilustrada/2018/07/encontro-deautora-do- movimento-negro-e-escritora-que-trata-de-feminicidiovira-palanque-feminista.shtml>. Acesso em: 5 junho 2019. 
RAMONET, I. Meios de comunicação: um poder a serviço de interesses privados? In: Moraes, D; Ramonet, I; Serrano, P. (Org.). Mídia, poder $e$ contrapoder: Da concentração monopólica à democratização da informação. 1ed. São Paulo: Boitempo Editorial, 2013.

RAMONET, I. A explosão do jornalismo na era digital. In: MORAES, D; RAMONET, I; SERRANO, P. (Org.). Mídia, poder e contrapoder: Da concentração monopólica à democratização da informação. 1ed. São Paulo: Boitempo Editoral, 2013.

RESENDE, F. A. Falar para as massas, falar com o outro: valores e desafios do jornalismo. In: FrançA, V.; CORRÊA, L. (Org.). Mídia, instituições e valores. 1ed. Belo Horizonte: Autêntica, 2012, pp. 153-165.

Rodríguez, J. J. Comunicación, ética y feminicidio: Contextos de la crisis de representación en la prensa de México. Cuadernos Intercambio sobre Centroamérica y el Caribe, v. 14, n. 2, 2017, pp. 19-30. Disponível em: <https: / /www.redalyc.org/articulo.oa?id=476954689002>. Acesso em: 5 junho 2019.

Rovetto, F. La representación del trabajo de las mujeres en las noticias de actualidad. Análisis comparado de la prensa española y argentina. La Trama de la Comunicación, v. 16. UNR Editora, 2012. Disponível em: https: / / latrama.fcpolit.unr.edu.ar/index.php/trama/article/view/41. Acesso em: 5 junho 2019.

SAfIOTTI, H. I. O poder do macho. São Paulo: Editora Moderna, 1987.

SAloRenzo, L. Gramática da Manipulação. Belo Horizonte: Quintal Edições, 2018, p.123.

SANTOS, M. T. A.; GoRovitz, S. Cultura e Tradução jornalística: Uma Abordagem Teórica. Diálogos Pertinentes- Revista Científica de Letras. v. 9, n. 2, 2013, pp. 9-26. Disponível em: <http://publicacoes.unifran.br/index.php/dialogospertinentes/article /view/784>. Acesso em: 5 junho 2019.

Simão, A. K. G.; Stupiello, E. N. A. Repensando a (in) visibilidade do tradutor: propostas para o contexto de formação acadêmica em tradução. Caracol, n. 14, São Paulo, 2017. Disponível em: <https://www.revistas.usp.br/caracol/article/view/135285>. Acesso em: 5 junho 2019.

VENUTI, L. Tradução, Simulacro, Resistência. Trad. Roberto Mário Schramm Jr. In: Blume, R. F.; Peterle, P. (Org.). Tradução e relações de poder. Tubarão: Ed. Copiart; Florianópolis: PGET/UFSC, 2013. 
Von FLotow, L. Traduzindo mulheres: de histórias e re-traduções recentes à tradução "Queerizante"e outros novos desenvolvimentos significativos. Trad. Tatiana Nascimento dos Santos. In: Blume, R; F.; PeterLe, P. (Org.). Tradução e relações de poder. Tubarão: Ed. Copiart; Florianópolis: PGET/UFSC, 2013. pp. 169-192.

ZIPSER, M.E; AIO, M.A. Tradutor jornalista ou jornalista tradutor? A atividade tradutória enquanto representação cultural. Gragoatá, Niterói, n. 31, 2011, pp. 107-118. Disponível em: <https://doi.org/10.22409/gragoata.v16i31.33052>. Acesso em: 5 junho 2019.

ZIPSER, M. E.; PolChloPeK, S. A. A tradução de notícias: novos rumos para a pesquisa em tradução. Tradução \& Comunicação, n. 15, 2006, pp. 4553. https://revista.pgsskroton.com/index.php/traducom/article/view/21 96. Acesso em: 5 junho 2019. 